\title{
Development of Piezoelectric as One of the alternatives for Marine Wave Energy in Indonesia
}

\author{
Ede Mehta Wardhana ${ }^{1, a, *}$, Meitha Soetardjo ${ }^{2, b}$, Wisnu Wardhana ${ }^{3, c}$ and M. Badrus Zaman ${ }^{1, d}$ \\ ${ }^{1}$ Department of Marine Engineering, Institut Teknologi Sepuluh Nopember, Indonesia \\ ${ }^{2}$ Agency For Assessment And Application Of Technology, Surabaya, Indonesia \\ ${ }^{2}$ Department of Ocean Engineering, Institut Teknologi Sepuluh Nopember, Indonesia \\ a.edewardhana123@gmail.com,b.meithasoetardjo@gmail.com, c.wisnuwardhana2@yahoo.com, \\ d.drus_zaman@yahoo.com \\ *corresponding author
}

Keywords: electric energy; energy production; mechanical structure; piezeolectric; strain energy; wave to wire.

\begin{abstract}
As one of the tools in the field of Energy Production, Piezoelectric is one of the most reliable and efficient system on the renewable energy. These systems holds many potential for reducing the consumption of oil and gas energy because the system will generate electricity from natural resources. For piezoelectric materials when pressed, the atomic structure inside the material will change, and thus cause the formation and spate of the dipole moment. This formation will produce changes especially in the voltage differences across piezoelectric materials. This process is called a direct piezoelectric effect. Piezoelectric materials can be integrated into the system without difficulty. This is because the material will not have moving parts, so it will not require frequent maintenance. Moreover, the piezoelectric also has the potential capability to change and convert into the electrical energy that came from strain energy applied to the system. Those converting process also could be done with direct motion and no addition at all. In addition, the material is also capable of producing power at a certain level of stress that can be easily conditioned and achieved. When using the piezoelectric material, it is usually consist of various object that have the mass that also installed to a spring, silencer and also another model as its structure. Those installaion will operates when the object itself have an external resonant frequency that could came from various sources, the results of those frequency will make the model move into a linear motion and will create energy to be accessed by another process.. The objective of the study was to find out whether the application of Piezoelectric is suitable for Renewable Sea Energy in Indonesia using wave-to-wire modeling technique.
\end{abstract}

\section{Introduction}

An increase in population for people in Indonesia will produce more energy production as needed. However, more traditional energy consumption has led to serious energy crises and environmental pollution on a global scale. Alternatives to solve the fossil fuel crisis and environmental pollution use 
technology from alternative energy and / or renewable energy. Compared to fossil fuel energy sources, alternative and renewable energy will results in a less waste and pollutants such as $\mathrm{CO}_{2}$, $\mathrm{NOx}, \mathrm{CH}_{4}$, and another harmful substances. Thus, by reducing pollution will mean that the negative effects on the environment are as low as possible.

Due to the geographic condition in Indonesia itself, the alternative for the most potential and beneficial renewable energy types is the marine renewable energy (MRE). Among MRE, wave energy production is considered one of the most potential alternatives due to the result of various experiment. The high value of the density and its power becomes the main focus why this type of alternative and renewable energy is very popular. Other than those, it also have a good efficient way to harvesting and converting the natural energy resources. The capabilities that could be produced from these energy is estimated will be higher than 2 TW. However the research and products with the ocean wave energy is still far from perfect and have various problems.

Many major problems that could occur in system came from the harvesting energy process. Based of all available mechanical-to-electrical energy conversions, for example like the transduction from the electrostatic, electromagnetic and the piezoelectric, the total sum of energy density that came from the transduction that used piezoelectric is much better than the others. In fact, if constructed correctly, the energy density results can be more than three times of energy that came from transduction of electrostatic and electromagnetic transduction [1] [2]. More than those benefit, the whole structure from the system that used piezoelectric as its transducer is much easier to assembly than normal generators in general. In the past, there are some models of piezoelectric materials in both energy generation and absorbtion energy, whether it is on wind energy or wave energy have analyzed [3] [4] [5]. The piezoelectric material device is one of the smart ingredients that produce a direct piezoelectric effect. This effect affects the inner process of generating electrical charges.

Many Experiments nowadays are focusing on the power that came from the ocean waves. The process of ocean waves to the power grid based on all components including: investigating system dynamics, optimizing tool performance and improving the overall efficiency. All of the process must be done simultaneously as a requirement in order to make the system feasible. The whole process from converting the power of ocean waves to elctrical energy is called to as "wave to wire" (W2W). those proess has various inputs and outputs derived from the marine energy conversion system especially wave energy, where electricity that produced based from the model will be transmitted to the network or supplied to an electric machine. The interaction between hydrodynamics, mechanical and electrical parts as well as clutch parts will also be analyzed from the model. The more advanced of the strategic control also becomes one of the advantage of using the system, those control can be installed in the W2W model. This will result in an increase of system performance, to comply with the standards of the grid code, and also to match the operation requirements of the subsystem from the whole process.

The Wave to Wire model is categorized into four stages, and those are :

- Harvesting Energy process stage

- Power Generation process stage

- Electrical Transmission process stage and

- Conditioning stage.

All sub-equipments from the wave to wire model will always be related to these four stages. The objective from the research is to check whether the research, model and innovation from nowadays based on Wave to Wire method that added with an installation of the piezoelectric device could be analyzed and whether these additions/replacements will suitable with the condition in Indonesia or not is suitable, available or can be assembled 


\section{Design and Modeling Methods}

\subsection{Numerical calculation}

Various wave-to-wire models from tools such as converter of the wave enegy devices have been researched and all of these studies are focused on energy conversion processes. References [6] - [10] describes the various types of water column oscillating WECs using an air turbine generator, WECs that used a component called direct-drive rotation generators, WEC also installed at the top with a turbine generator with water as its fluid, and WEC that utilized the so called direct-drive linear generators. From all of these studies, understanding has been gained through all of these researches primarily about the motion and the modifying the a movement from a WEC unit. Based on these experiments and various types of WEC it is ensured that one of the most efficient wave converters is unclear and depends on the geographic conditions of the installation location. Based on these studies also, it became clear that not much published research has focused on the controlled response of the equipment that directly attached to a limited grid. the schematic model of a WEC based on the inputprocess-output diagram is shown in Figure 1. While the schematic structure for the waves for the wire model using numerical calculations is shown in Figure 2. Where the numbers on the numerical calculations are based on the frequency domain and time domain of the wave model.

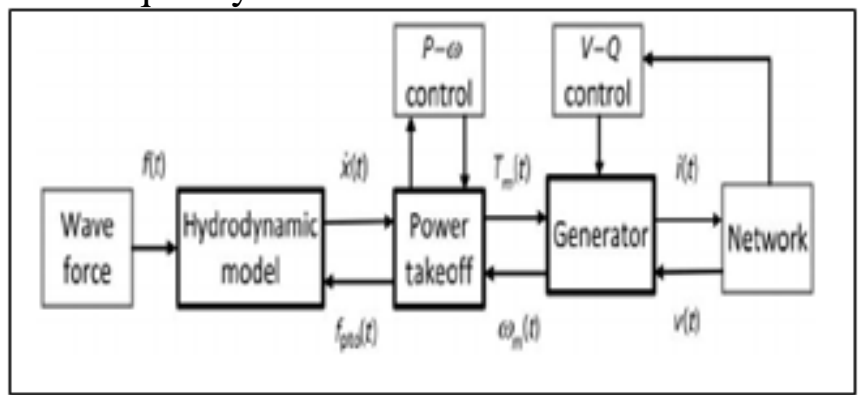

Figure 1. Diagram schematis of a W2W from a single WEC.

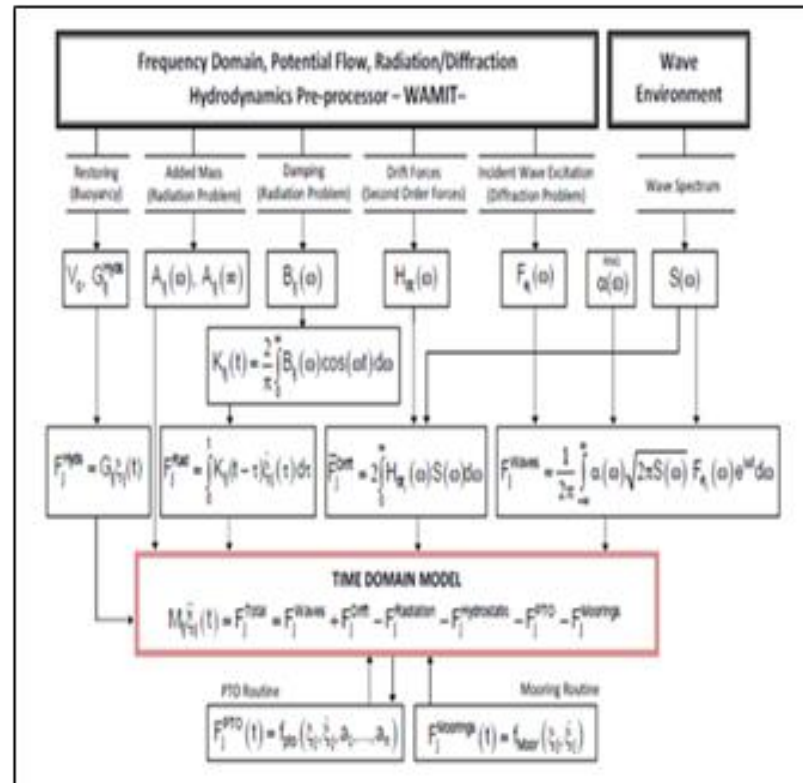

Figure 2. Schematic of a numerical calculation of the W2W of a single WEC 


\subsection{Ocean Wave Energy}

In order to generating energy from the ocean waves, it can be done using various mechanisms, including the platenary forced or even the earthquake from the sea. However, the most suitable wave energy conversion are done by wind that is moved over to an area of a fluid from a container in a surface plates, called as wind waves. Because of those winds, the velocity of the ocean waves will depends on two things. One is the wavelength that came from the period and frequency, Two is the whole depth of the ocean where the equipment is installed. Those two things will become the main parameter for the calculation which could be expressed through these formula.

$$
v=\sqrt{\frac{g \lambda}{2 \pi}} \tan h\left(2 \pi \frac{h}{\lambda}\right)
$$

Where the $\lambda$ is the wavelength, $h$ is the height or depth of the sea, measured from the sea bed until the surface of the se, and $g$ is the acceleration of gravity and $\pi$ is in radial. The energy equation parameter could be seen on the figure shown in Figure 3.

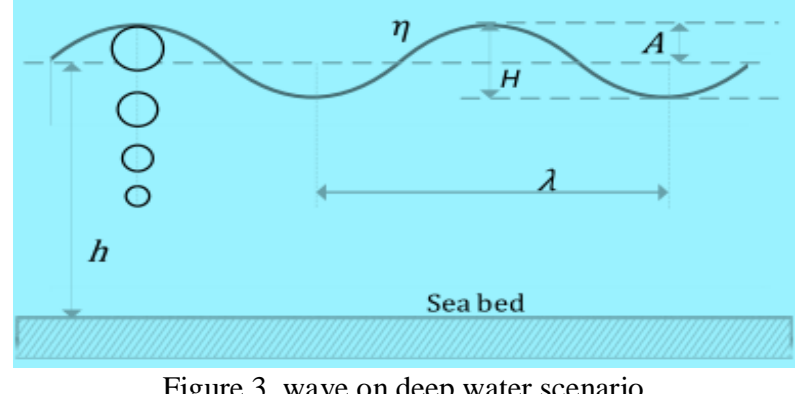

Figure 3. wave on deep water scenario

Around $90 \%$ of all available wave energy could came based on the depth (between the sea surface and the sea bed). And those also almost the same as $1 / 4$ of the wavelength in a deep water case for the wavelength calculation

From the formula (1) will show around $90 \%$ of the energy from the ocean wave energy is available from around the surface and the ocean depth equals about $1 / 4$ of the wavelength. Those quarter also based on the deep water situation for wavelength calculations [11]. The formula of total energy in those scenario could be calculated using the equation :

$$
E=\frac{1}{\lambda} \int_{0}^{\lambda} \int_{0}^{1} \frac{1}{2} g p \eta^{2} d x d y+\frac{1}{\lambda} \int_{0}^{\lambda} \int_{0}^{1} \int_{-\infty}^{0} \frac{1}{2}\left(v_{x}^{2}+v_{y}^{2}+v_{z}^{2}\right) d x d y d z
$$

Where $\lambda$, is the elevation that comes from the wave, $\rho$ is the ocean water density, $v_{x}{ }^{2}+v_{y}{ }^{2}+$ $v_{z}{ }^{2}$ are the velocity in the direction of $\mathrm{x}, \mathrm{y}, \mathrm{z}$ axis. Those equation are the combination between two kind of energy which are the kinetic and potential energy.

In circumstances where the the environment is quite restricted, usually as tools it could be used with JONSWAP spectrum. Joint North Sea Wave Project (JONSWAP) created this spectrum in order to calculate the restricted condition and limitation that available on the Northe Sea. It is expressed as : formula (3) and the energy per unit area of sea surface amounting to an average in the irregular case is expressed as : formula (4).

$$
\begin{aligned}
& S(w)=\frac{5}{16} H_{s}{ }^{2} \frac{W_{0}{ }^{2}}{w^{5}} e^{-\frac{5}{4}\left(\frac{W_{0}}{w}\right)^{4}} \\
& E=2 \rho g \int_{0}^{\infty} S(f) d f
\end{aligned}
$$


Whereas $\mathrm{w}$ is the value of the angular frequency with the units as the radians per second, wo is the frequency that comes from the wave on various direction, Hs is the wave height (significant / the one that is used / modeled in the system), $\mathrm{f}$ is the frequency in hertz.

\subsection{Power Take Off - State of the Art}

\subsubsection{Direct Mechanical Drive System (DMDS)}

Direct Mechanical Driven System is a tools with power take off in a direct motion. The tools will used the mechanical connectors on a WEC that connected with its moving components. The connection will be connecting the electrical generator and to the moving components. The electricity from the generator itself could be roduced using a rotating generator or the generator that used the linear motion. One of the mechanical connectors that will be used in this system is like the lines (from a mooring), chain, a gearbox, a pulley, etc. One of the weakness from this system is because of its motion, there will be need a compensatiton between using storage and frequency converter systems that will resulted on the fluctuation of the velocity. One of the example from the storage system is electrochemical cells or batteries system. The example of the existing system that used this kind of PTO is The Uppsala Point Absorber that utilized a linear electrical generator. Those generator will be operated by the relative velocity that occured between the model that floats on the surface and a reaction fixed on the seabed.

\subsubsection{Water Turbine Systems}

There will be a conversion between potential into mechanical energy on this syste. The water turbine will be used as one of the main tools for the system operation. Because the main source came from the turbine (using water as its fluid), the whole power that produced from the device will rely on the available head from the system, and also its flux. The system also neds the hydraulic pumps which can generate a high head and high pressure that could be processed and utilized by one of the installed turbines. The most common used for the turbine is the Pelton Turbines. This case and PTO has been analyzed by two big project, which are the Oyster project and the CETO project. The example of the system that used this PTO is the Wave Dragon or SSG. Those are using the water in a storage based from the collection of the seawater in an elevated basin, and also have various head range from $1 / 2$ meter to a few meter high.

\subsubsection{Hydraulic System}

Hydraulic Fluid for driving a hydraulic moto is one of the most common Power Take off used in MRE. The system will rotate a rotating electrical generator in order to produce electricity. For the hydraulic, it could be used fresh water or oil (according to the standard) and it will be pressurized from another material such as piston, after the pressure is enough the fluid will be transferred by hydraulic motor or water turbine in order to drive an electricity generator. Hydraulic PTO have many benefit such as could collect and used fluid form various sources, robust and durable, able to operate on high loads for a very long time. The piston on this system usually a double acting cylinder added with a valve like a check valve and/or directional valves that used to handle the flow to the motor itself. It also could be a variable or fixed volume or use a high value of the head impulse water turbine and connects with a rotating generator. Related with this sort of PTO is the requirment to discover arrangements for the "end-stop problem"- an arrangement that guarantees that the actuator will be secure within some requirements and standard. The water powered PTO framework is utilized in several application as point absorbers (Wavestar, CPT, AquaBUOY, Pick, Wavebob), attenuator (Pelamis, Dexadevice), terminator (Shellfish). A distinctive method is displayed by Costello [12], 
and Kamizuru [13] where a direct driven pressure driven engine is utilized evacuating the aggregator and able to rolling the result output as it were within the generator side

The system that will be used in these research is based on the Hydraulic System.

\section{Literature Review Of Piezoelectric Materials For Ocean Energy}

The subject that being experimented upon are method of extraction, the source of energy and type of piezoelectric materals used in the experiment. Those technology is far from the balance and economically good phase. Although the research of the piezoelectric still haven't found the steady state phase for the technology, recent research has shown a promising results in the generation of power from various models and different shape of the piezoelectric.

Based on the previous research, there are 5 method of extraction from Piezoelectric Devices For Ocean Energy, those method are :

- Flow Induced Vibrations - The method have different types for the harvest of energy which called as the 'Vortex Induced Vibrations' and ' Self-Excited Vibrations'. Taylor et al [22] have proposed his research with an "eel shaped" model for his small subsurface river power generator. It have of a model and a piezoeletric will be installed behind it, the vortex will be generated due to the waves that hit the body of the model and finally press the piezoelctric to generate the power from those wave energy converter models.

- Cantilever Flow-Induced Vibrations - The method on this type is using PVDF beam in unsteady turbulent air flows [23]. The general method of these is shown in Figure. 4 :

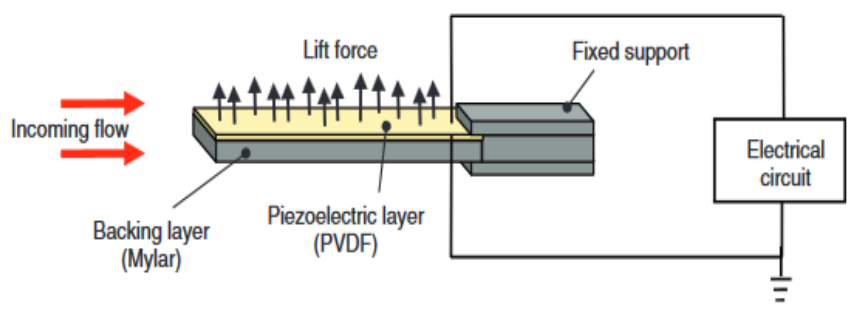

Figure 4. Cantilever Flow-Induced Vibrations [23]

The incoming flow from the waves will hit the cantilever that is installed with the piezoelectric materials. That hit will come from the force of the wave energy and generated the power of it

- Heaving and Pitching Mode Harvester - Falnes et al [24] begin the oscillating system which harvests the energy based on the heaving and pitching motion. However, the result itself isn't satisfactory to accompany the needs for the power. Thus, Murray et al [25] create a two-stage method to generate the power that contains within the wave. With the wave motion as the primary source to move the mechanical model, and the model will hit the piezoelectric materials to generate the power. The model is shown in Figure 5 


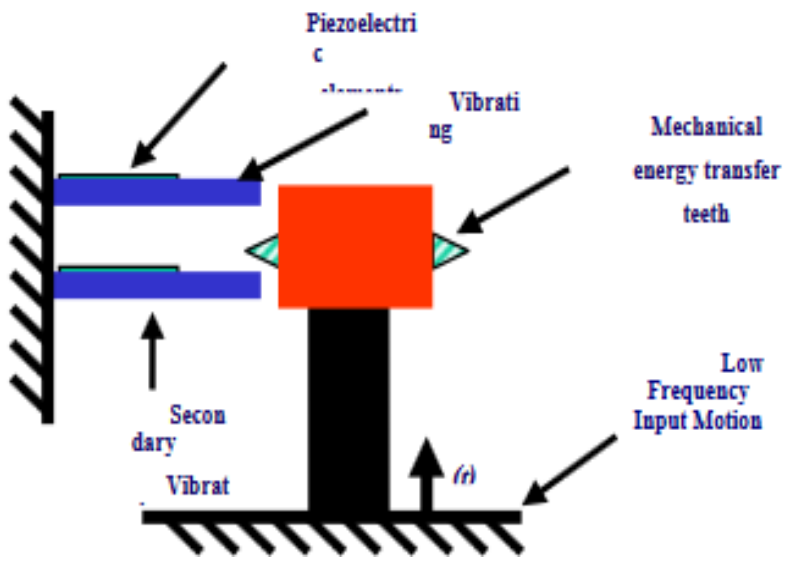

Figure 5. Cantilever Flow-Induced Vibrations [25]

- Bodies Mounted to the Ocean Bottom - the ideas in this system are to use the piezoelectric polymers (such as PVDF) installed in a shallow sea bed from [26]. Water particles from the waves will have more velocities both on horizontal axis and also the vertical axis if the model closer to the sea surface. Therefore, the piezoelectric cantilever beam will tend to become more bend than usual, and consequently will produce more power than the common model. Another experiment by Xie et al [27] is modified the experiment from before, where the model is extended to the surface to generate more power from the wave motion. The figure for these model is shown in Figure 6. The model is made using PVDF materials installed within the foam core and extended until the ocean surface from a shallow water. The power that is generated is based on the energy extraction from the coupling installation from the PVDF materials to the linear motion of the wave motion that came from the ocean.

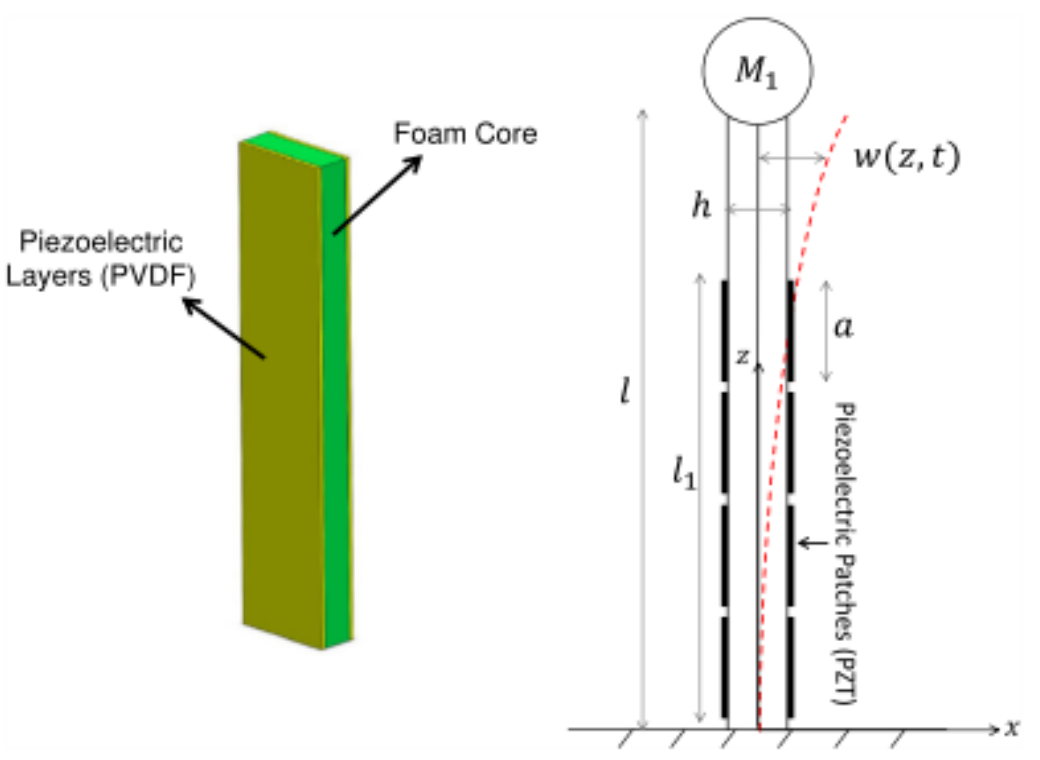

Figure 6. Bodies mounted at the bottom by f Zurkinden et al. [26](left) and Xie et al. [27] (right)

- Wave Impact: Sloshing - Sloshing is used based on the ideas of installing the materials in a very vertical cliff. The ideas are implemented by Athanassoulis and Mamis [28]. Based on the author research, it has 2 advantages: to generate power from the renewable sources and to damp the internals loads that came from the sloshing of the water 


\section{Review Of Wave To Wire Model In Indonesia Marine Wave Energy Condition}

Based on the hydraulic PTO, more innovative of the control strategies could be done with modifing and control the generator or the hydraulics equipment. For the example, is the Wavestar WEC. Movement and force in this device will be influenced by the strandard of the generator force. Those forces that comes from the generator will therefore also influence the motor displacement. The effect of the changes of the displacement will result to a change on a force that comes from the actuator and cylinder. Some element on th hydraulics such as the cylinder, valves, motor and accumaulator could be modified and accustomed from the change of the pressure. Change of that will result a difference in hydraulic circuits and will result of the change for the force. With these elements, different hydraulic circuits will be control to implement the management methods [21].

While many of the wave energy converter prototype in Indonesia generates a direct transmission from the wave to the electrical system, there still not many prototype that using the piezoelectric devices. Some of the research regarding the piezoelectric is done by utilizing the thin layer of the piezoelectric material and combining those with the covered layer to make the flexible piezoelectric device. The schematics and overview of those could be seen on Figure 7. However, the type to analyze in these research is the cantilever types with a metal ball installed on the device, the ball will roll and move according to the height of the wave. The schematics of the prototype is shown in Figure 8 .

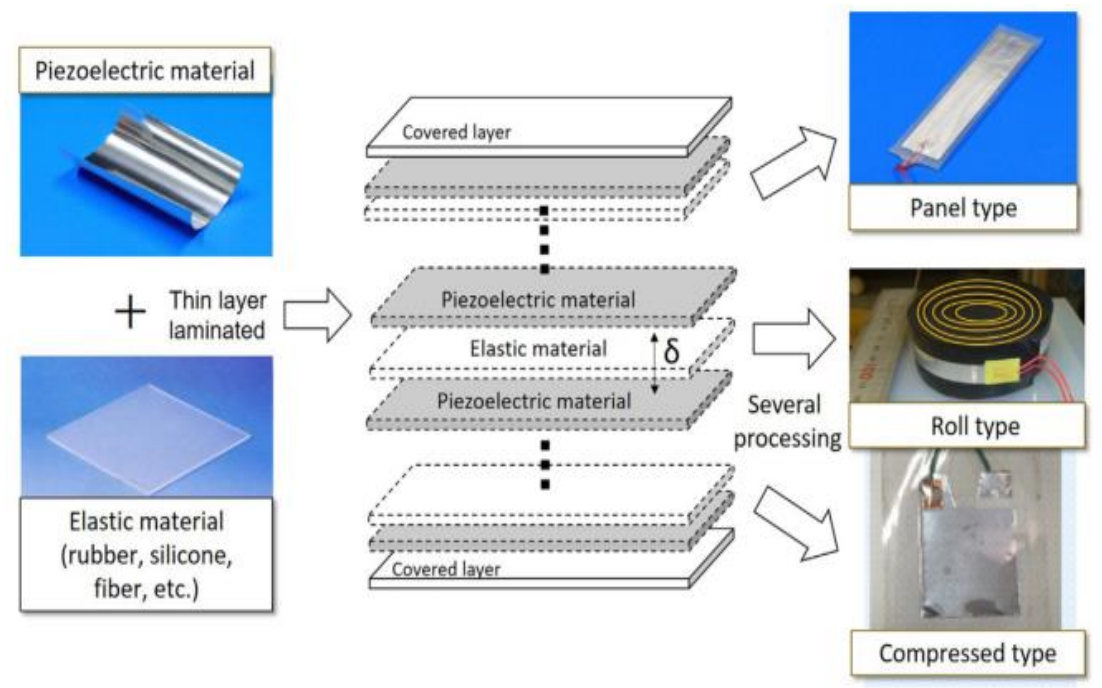

Figure 7. overview of the flexible piezoelectric device [14] - [17]. 


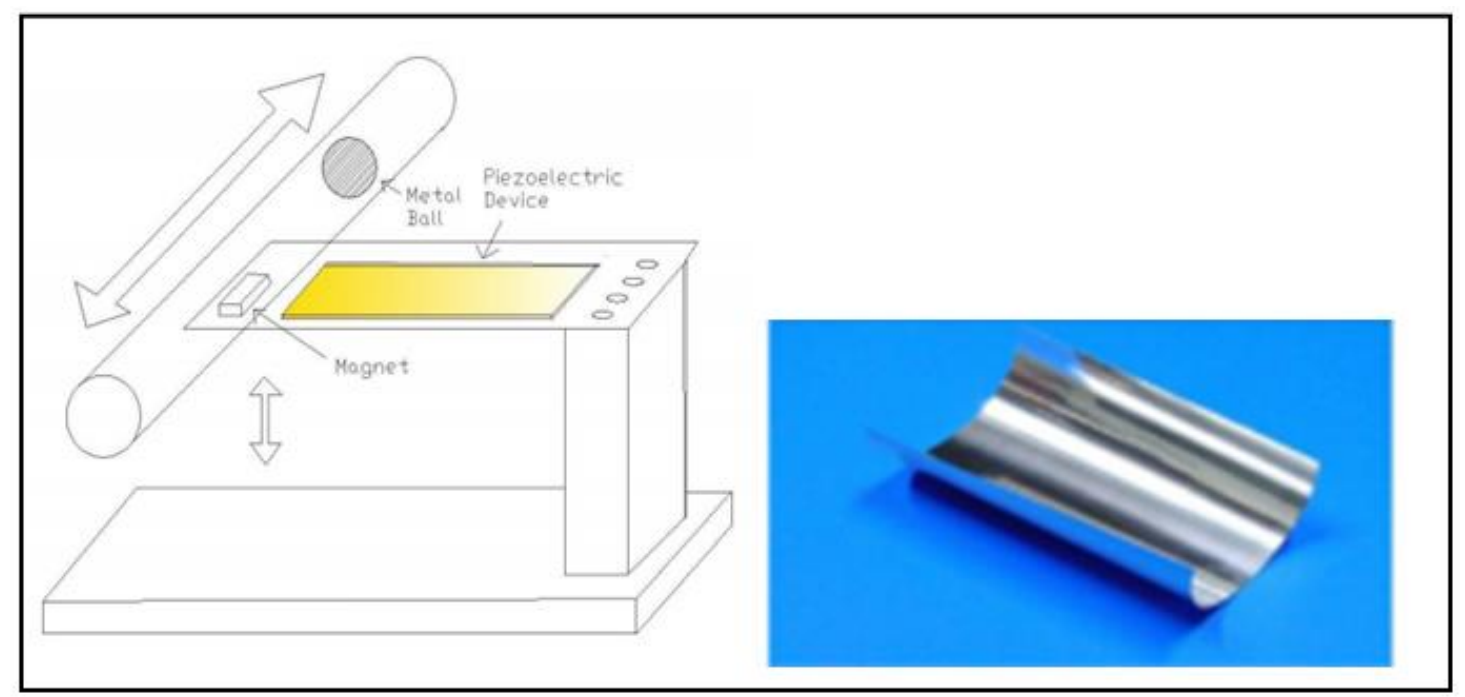

Figure 8. overview of the proposed piezoelectric device. Combination of two method of piezoelectric devices.

As shown in Fig. 8, piezoelectric wave converters are made of basic cantilevered structures with magnet installed within the system to the end of the module. On the top of the magnet, there will be a circle tube which the magnet ball can move from one end to another end. When the model is tilted at an angle due to period and frequency difference by ocean waves resulting in different heights, the metal ball will roll over inside the tube. The rolling motion will produce vibrationloflthel piezoelectriclmodulel located betweenlthelballl andlthel magnetlinsidelthelmodel. The piezoelectric material itself isn't a conventional material but the newest materials which called as the Flexible Piezoelectric Materials Devices (FPED) which already resulted in a higher generated power when pressed with enough mechanical stress. Even during the impact of the harvester with a metal ball, the device will remain structured structurally due to the maximum vibration displacement constraint caused by the rail length. The proposed tool will study the condition of "wobble" captured in the oceans. Based on previous studies using piezoelectric devices [14] - [15] the minimum values of altitude need to be about $1.0 \mathrm{~m}$. Based on data from BMKG and research [18]. The corresponding locations in Indonesia are shown in Figure 9.c.
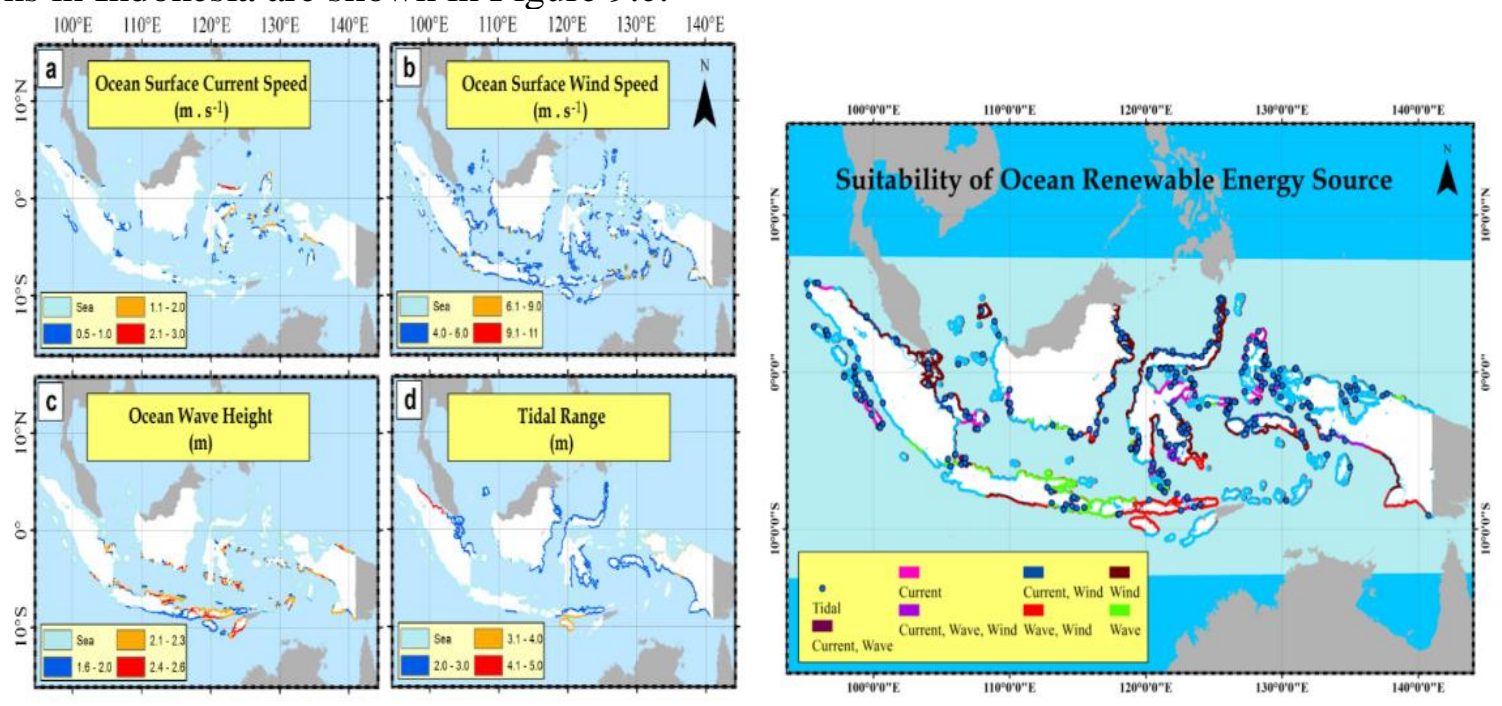

Figure 4. Estimated suitable location in Indonesia

Control methods and their validation for WECs particularly the one with the piezeolectric device each using both numeric and experiment ways are shown in section III and IV. These ways apply management in first absorbtion system and also the power trade off system, while many of those are 
often enforced within the W2W model. But, it ought to be seen that almost all of the numeric and math models employed in the calculation of the analysis don't contemplate the losses within the real system, as well as the hydraulics loss, loss of the mechanics, and therefore the losses because of the electric. The research of the influence that came because of the losses from the electrical is shown in [19], wherever the management, the electrical efficiency and therefore the total efficiency are measured to more common solutions through a direct loss model with also seen into estimation about the electrical losses. Another example is introduced in [20. These results indicate that all inefficiency will create in more error and it will greatly influence the system efficiency. Another problem that occured is that the majority of those research solely specialize in the applying of management ways to one half or many elements of the total conversion system. for instance, the hydraulics management is simply one a part of the world improvement of the system efficiency. This management on a separate half, while not considering the coupling with the facility take-off half and therefore the grid or load half, will result in most energy absorption, however perhaps not the most world potency. it's additionally worthy to notice that despite overcoming those technical losses, the renewable energy production in land remains have many ways to travel.

Other issues in Indonesia that could be inserted into W2W model,such as the the cost, the reliability, and the physical constraints. The cost will include the production cost, the maintenance cost and the operation cost. While the reliability of the devices needs to be analyzed more thoroughly since every spots on the different location in Indonesia will have various and different problems such as the robustness of the equipment. While the power smoothing will always relies on the technological development and the physical constraints will needs various research and trial-and-error process in order to find the most efficient one.

\section{Conclusion}

This review of the Wave to Wire model calculation demonstrates that different conversion system that utilized ocean energy outlined to absorb sea wave energy and change over into electricy with various control strategies. While various could be validated on those, one of the innovative way to capture the energy, which is to use the piezolectric device is considered on of the better alternatives to use in future research. The energy transformation from sea waves to electric control comprises of different and different parralel components.

Because these renewable energy is used on the sea, it needs those various components to transfer and change the type of the energy into electrical energy. In order to change that, it needs the components from the mechanical equipment, the machines with electrical and the control electronic converters. The execution of the whole transformation framework will seen on parameter such as physical characteristics and control techniques. These development is still in the early beta process. And in order to test its validation the prototype itself needs to be experimented based on the condition on several location in Indonesia.

\section{References}

[1] Williams. C.B, Yates. C.B. (1996) Analysis of a micro-electic generator for microsystems. Sens Actuators A. 1996;52:8-11

[2] Priya S. (2007). Advances in energy harvesting using low profile piezoelectric transducers. J Electroceram., 19:165-82.

[3] Anton, S. R., \& Sodano, H. A. (2007). A review of power harvesting using piezoelectric materials. Smart Materials and Structures, 16. R1-21.

[4] Cook-Chennault, K. A., Thambi, N., \& Sastry, A. M. (2008). Powering MEMS portable devices - A review of non-regenerative and regenerative power supply systems with special emphasis on piezoelectric energy harvesting systems. Smart Materials and Structures, 17, 043001. 
[5] Kim, H. S., Kim, J. H., \& Kim, J. (2011). A review of piezoelectric energy harvesting based on vibration. International Journal of Precision Engineering and Manufacturing, 12, 1129-1141.

[6] M. Amundarain, M. Alberdi, A. J. Garrido, and I. Garrido, "Modeling and simulation of wave energy generation plants: Output power control,” IEEE Trans. Ind. Electron., vol. 58, no. 1, pp. 105-117, Jan. 2011.

[7] P. Igic, Z. Zhou, W. Knapp, J. MacEnri, H. C. Sørensen, and E. FriisMadsen, "Multi-megawatt offshore wave energy converters electrical system configuration and generator control strategy," IET Renew. Power Gener., vol. 5, no. 1, pp. 10-17, 2011.

[8] E. Tedeschi, M. Carraro, M. Molinas, and P. Mattavelli, "Effect of control strategies and power take-off efficiency on the power capture from sea waves," IEEE Trans. Energy Convers., vol. 26, no. 4, pp. 1088-1098, Dec. 2011.

[9] W. Feng, X. Zhang, P. Ju, and M. J. H. Sterling, "Modeling and control of AWS-based wave energy conversion system integrated into power grid," IEEE Trans. Power Syst., vol. 23, no. 3, pp. 1196-1204, Aug. 2008.

[10]P. B. Garcia-Rosa, J. P. V. S. Cunha, F. Lizarralde, S. F. Estefen, I. R. Machado, and E. H. Watanabe, "Waveto-wire model and energy storage analysis of an ocean wave energy hyperbaric converter, " IEEE J.Ocean. Eng., vol. 39, no. 2, pp. 386-397, Apr. 2014.

[11]Ilyas A, Kashif SAR, Saqib MA, Asad MM. Wave electrical energy systems: implementation, challenges and environmental issues. Renew Sustain Energy Rev 2014;40:260-8.

[12]Costello, R., Tingwood, J. V., \& Weber, J. (2011). Comparison of Two Alternative Hydraulic PTO Concepts for Wave Energy Conversion. Southampton: EWTEC.

[13]Kamizuru, Y., Lermann, M., \& Murrenhoff, H. (2010). Simulation of an ocena wave energy converter using hydraulic transmission. Aachen: International Fluid Power Conference.

[14]H. Mutsuda, M. Hirata, R. Watanabe, Y. Doi, Y. Tanaka, Elastic floating unit with piezoelectric device for harvesting ocean wave energy, Proceedings of the ASME 31st International Conference on Ocean, Offshore and Arctic Engineering, vol. 7 (2012) 233-240, http://dx.doi.org/10.1115/OMAE201283318.

[15]H. Mutsuda, R. Watanabe, S. Azuma, Y. Tanaka, Y. Doi, Ocean power generator using flexible piezoelectric device, Proceedings of the ASME 32nd International Conference on Ocean, Offshore and Arctic Engineering, vol. 8 (2013),http://dx.doi.org/10.1115/OMAE2013-10078, V008T09A002.

[16]H.Mutsuda, J. Miyagi, Y. Doi, Y. Tanaka, H. Takao, Y. Sone, Flexible piezoelectric sheet for wind energy harvesting, Int. J. Energy Eng. (2014) 67-75.

[17]Y. Tanaka, T. Oko, H. Mutsuda, A.A. Popov, R. Patel, S. McWilliam, Forced vibration experiments on flexible piezoelectric devices operating in air and water environments, Int. J. Appl. Electromagn. Mech. 45 (2013) 573-580.

[18]Noir P. Purba, Jaya Kelvin, Rona Sandro, Fatimah Maulida, Syahrir Gibran, Marine K. Martasuganda, Resti A.I. Permata. Suitable Locations of Ocean Renewable Energy (ORE) in Indonesia Region - GIS Approached, Energy Procedia 65 ( 2015 ) 230 - 238.

[19]Hong Y, Waters R, Boström C, Eriksson M, Engström J, Leijon M. Review on electrical control strategies for wave energy converting systems. Renew Sustain Energy Rev 2014;31:329-42.

[20]Mendonça H, Martinez. S. Energy conversion efficiency assessment of a direct drive wave energy converter with different current controllers, in 2016 IEEE International Energy Conference (ENERGYCON); 2016, p. 16.

[21]Liguo Wang, Jan Isberg, Elisabetta Tedeschi. Review of control strategies for wave energy conversion systems and their validation: the wave-to-wire approach. Renewable and Sustainable Energy Reviews 81 (2018) 366379

[22]G. W. Taylor, J. R. Burns, S. A. Kammann, W. B. Powers, and T. R. Welsh, "The Energy Harvesting Eel: a small subsurface ocean/river power generator,” IEEE J. Ocean. Eng., vol. 26, no. 4, pp. 539-547, Oct. 2001.

[23]H. D. Akaydin, N. Elvin, and Y. Andreopoulos, "Energy Harvesting from Highly Unsteady Fluid Flows using Piezoelectric Materials, Energy Harvesting from Highly Unsteady Fluid Flows using Piezoelectric Materials, "J. Intell. Mater. Syst. Struct., vol. 21, no. 13, pp. 1263-1278, Sep. 2010.

[24]J. Falnes, "Ocean Waves and Oscillating Systems by Johannes Falnes," Cambridge Core, Mar-2002. [Online]. Available: /core/books/ocean-waves-and-oscillatingsystems/8A3366809DE5C1F916FF87F36C55C459. [Accessed: 12-Jul-2018].

[25]R. Murray and J. Rastegar, "Novel two-stage piezoelectric-based ocean wave energy harvesters for moored or unmoored buoys," in Active and Passive Smart Structures and Integrated Systems 2009, 2009, vol. 7288, p. $72880 E$.

[26]A. S Zurkinden, F. Campanile, and L. Martinelli, "Wave Energy Converter through Piezoelectric Polymers," 2013.

[27]X. D. Xie, Q. Wang, and N. Wu, "Potential of a piezoelectric energy harvester from sea waves, "J. Sound Vib., vol. 333, no. 5, pp. 1421-1429, Feb. 2014.

[28]G. Athanassoulis and K. Mamis, "Modeling and analysis of a cliff-mounted piezoelectric sea-wave energy absorption system,” Coupled Syst. Mech., vol. 2, pp. 53-83, Mar. 2013 